\title{
ATIVIDADE PRÁTICA NO ENSINO DE GEOGRAFIA FÍSICA COM ALUNOS CEGOS E BAIXA VISÃO:UM MODELO TÁTIL DE UMA BACIA HIDROGRÁFICA
}

\section{Practical activity in the teaching of physical geography with blind students and low vision: A tactile model of a hydrographic basin}

Actividad práctica en la enseñanza de geografía física con estudiantes ciegos y baja visión: Un modelo táctil de una cuenca hidrográfica

\section{Vicente Passaglia Pereira Cantanhede* Maryelle Florêncio Mariano**}

*Acadêmico do PPG em Geografia UNICAMP - vicentppc@gmail.com.

** Acadêmico do PPG em Geografia UNICAMP -marianomaryelle@gmail.com

Recebido em 12/10/2019. Aceito para publicação em 20/10/2019.

Versão online publicada em 10/11/2019 (http://seer.ufrgs.br/paraonde)

\section{Resumo:}

O presente trabalho traz uma proposta de atividade voltada para alunos com deficiência visual e baixa visão. Para isso foram utilizados recursos da cartografia tátil, a luz da teoria do profissional reflexivo de Schon (1983) foi confeccionado um modelo tátil de uma bacia hidrográfica, que pode ser utilizado em sala de aula. Espera-se com esse modelo explorar os potenciais de um modelo tátil e subsidiar aos professores exemplos de atividades que podem ser utilizados e adotados em suas práticas profissionais.

Palavras-chave: alunos com deficiência, teoria do profissional reflexivo, modelo tátil.

\begin{abstract}
:
The present work presents a proposal of activity aimed at students with visual impairment and low vision. For this, we used the resources of tactile cartography, the light of the theory of the reflective professional of Schon (1983) was made a tactile model of a watershed, which can be used in the classroom. This model is expected to exploit the potentials of a tactile model and to subsidize to teachers examples of activities that can be used and adopted in their professional practices.
\end{abstract}

Key-words: Students with disabilities, theory of the reflective professional, tactile model.

\section{Resumen:}

La presente obra presenta una propuesta de actividad dirigida a estudiantes con discapacidad visual y baja visión. Para ello, utilizamos los recursos de la cartografía táctil, la luz de la teoría del profesional reflexivo de Schon (1983) se hizo un modelo táctil de una cuenca hidrográfica, que se puede utilizar en el aula. Se espera que este modelo explote las potencialidades de un modelo táctil y subvencione a los profesores ejemplos de actividades que pueden ser utilizadas y adoptadas en sus prácticasprofesionales.

Palabras-clave: Estudiantes con discapacidad, teoría del profesional reflexivo, modelotáctil. 


\section{Introdução}

No que tange ao ensino de geografia, algumas estratégias podem ser utilizadas para inserir os conceitos geográficos aos alunos com necessidades especiais. Um exemplo de estratégia é utilizar um recurso da cartografia tátil, o mapa tátil. Esse recurso visa auxiliar os alunos cegos ou com baixa visão a perceber a representação do espaço.

Esse recurso pode ser utilizado de várias maneiras, tudo dependerá da necessidade do aluno, pois cada um possui um grau de percepção, sendo os alunos cegos aqueles que possuem a perda da visão, portanto não conseguem distinguir através desse sentido um mapa impresso, IBC (2014). Os alunos com baixa visão podem apresentar os mais variados níveis de perda visual, portanto podem vir a reconhecer as cores representadas em um mapa impresso, AMIRALIAN (2004).

O presente trabalho tem como objetivo propor uma atividade pedagógica, para alunos com deficiência visual e baixa visão a partir da temática bacia hidrográfica, foi realizado a confecção de um modelo tátil, a fim de auxiliar o professor de geografia em suas aulas. Esse modelo é confeccionado a partir de um mapa de cotas altimétricas a luz da teoria do profissional reflexivo de Schon (1983).

Esse modelo busca explorar as potencialidades do uso de modelos táteis nas aulas de geografia, com intuito de possibilitar a percepção espacial da área dessa bacia e alguns de seus componentes. Esses modelos táteis podem fornecer subsídios para o professor criar outros tipos de atividades e se colocar a refletir sobre a sua própria prática.

\section{Fundamentação teórico-metodológico}

A contribuição cartográfica é observada no ambiente escolar, em que o ensino da cartografia proporciona aos alunos a possibilidade de se alfabetizarem cartograficamente, considerando essa ciência como uma linguagem, os discentes podem ampliar os seus conhecimentos sobre a Geografia e proporcionar um ambiente de aprendizagem para si e para seus alunos.

Castellar (2005) ao expor seu ponto de vista da cartografia como linguagem, demonstra as potencialidades dessa ciência e as suas possibilidades transversais dentro da Geografia:

(...) uma linguagem, um sistema código de comunicação imprescindível em todas as esferas da aprendizagem em geografia, articulando fatos, conceitos e sistemas conceituais que permitem ser e escrever as características do território. Nesse contexto, ela é umaopção metodológica, que implica utilizá-la em todos os conteúdos da geografia, para identificar e conhecer não apenas a localização dos países, mas entender as relações entre eles, compreender os conflitos e a ocupação do espaço (Castellar, 2005, p. 216).

O mapa como instrumento de representação da realidade facilita as práticas educativas, dando ao professor inúmeras possibilidades de utilizá-lo e assim pode contribuir no processo de ensino aprendizagem do aluno

Um mapa é capaz de carregar informações que possibilitam elucidar problemáticas

ParaOnde!?, Porto Alegre, v.12 n.2, p.73-80, 2019.http://seer.ufrgs.br/paraonde Edição Especial -III Colóquio de Pesquisadores em Geografia Física Ensino de Geografia 
de um lugar, região e/ou espaço através de sua leitura e de seu entendimento, para isso a alfabetização cartográfica se faz necessária.

\begin{abstract}
Ler mapas, como se fossem um texto escrito, ao contrário do que parece, não é uma atividade tão simples assim, para que isso ocorra, faz-se necessário aprender, além do alfabeto cartográfico, a leitura propriamente dita, entendida aqui não apenas como mera decodificação de símbolos. As noções, as habilidades e os conceitos de orientação e localização geográficas fazem parte de um conjunto de conhecimentos necessários, juntamente com muitos outros conceitos e informações, para que a leitura de mapas ocorra de forma que o aluno possa construir um entendimento geográfico da realidade (Souza e Katuta, 2001, p. 51).
\end{abstract}

Esse modo de ler e entender os mapas, na maioria das vezes, parte de uma análise visual, porém não são todos as pessoas que possuem em perfeitas condições o sentido da visão, entre elas estão os cegos e os que apresentam algum comprometimento visual permanente que o classifica como baixa visão.

A definição de uma pessoa cega é dada pelo IBC (2014):

Perda ou redução de capacidade visual em ambos os olhos em caráter definitivo, que não possa ser melhorada ou corrigida com o uso de lentes, tratamento clínico ou cirúrgico. Existem também pessoas com visão sub-normal, cujos limites variam com outros fatores, tais como: fusão, visão cromática, adaptação ao claro e escuro, sensibilidades a contrastes, etc. (IBC, 2014).

A definição de baixa visão de acordo com AMIRALIAN (2004):

A baixa visão é considerada uma dificuldade visual de graus variáveis, que causa incapacidade funcional e diminuição do desempenho visual. Segundo esses especialistas, esta incapacidade não está relacionada apenas aos fatores visuais, mas é influenciada pela reação das pessoas à perda visual, e aos fatores ambientais que interferem em seu desempenho. (AMIRALIAN, 2004, p.21

Entendendo o grau visual de cada indivíduo, é importante propor ações inclusivas para que esses alunos, cegos e baixa visão, tenham dignidade e participem do processo de ensino aprendizagem. Para isso, é necessário um verdadeiro empenho em todos os setores, Glat e Blanco assinalam o que é necessário para atingir a inclusão:

Para tornar-se inclusiva a escola precisa forma seus professores e equipe de gestão, e rever as formas de interação vigentes entre todos os segmentos que a compõem e que nela interferem. Precisa realimentar, sua estrutura, organização, seu projeto-político-pedagógico, seus recursos didáticos, metodológicos e estratégias de ensino, bem como suas práticas avaliativas. Para acolher todos os alunos, a escola precisa, sobretudo, transformar suas intenções e escolhas curriculares, oferecendo um ensino diferenciado que favoreça o desenvolvimento e a inclusão social (GLAT e BLANCO, 2009, p.16).

Considerando essa perspectiva, o presente trabalho tem como mote os alunos deficientes visuais e indiretamente com baixa visão, para isso, sugere-se trabalhar com um mapa tátil, que pode ser de melhor análise para esses alunos, uma vez que a distinção dos elementos cartográficos se faz pelo tato.

A cartografia tátil traz esse diálogo com os materiais didáticos inclusivos, através do mapa tátil e a possibilidade de modelos táteis a partir de um mapa. Esse material é o mais adequado para representar um mapa com informações a um aluno com algum tipo

ParaOnde!?, Porto Alegre, v.12 n.2, p.73-80, 2019.http://seer.ufrgs.br/paraonde Edição Especial -III Colóquio de Pesquisadores em Geografia Física Ensino de Geografia 
de deficiência visual.

Não existe um conceito exato que defina um mapa tátil. O mais importante é respeitar as características de cada elemento pelos objetos táteis e que os mesmos encontram-se na legenda com sua descrição em braille (Almeida, 2008).

A pessoa com deficiência visual depende do sentido tátil para formar conceitos espaciais, entender informações geográficas e criar internamente imagens do ambiente. Para isso, o processo de transformação dos dados geográficos em mapas e diagramas precisa ser adaptado a um produto final especifico, através de uma linguagem tátil, preferivelmente combina visual. (...) A cartografia tátil pode, certamente, melhorar o entendimento dos mapas e a prática cartográfica (ALMEIDA, 2008, p.127).

Buscando uma proposta de atividade inclusiva, foi confeccionado um modelo tátil de bacia hidrográfica, sob a luz da metodologia do profissional reflexivo de Schon (1983), que sugere uma sistematização para o profissional refletir sobre a sua prática, colocandose assim sempre em formação. Essa teoria pode ser aplicada para o profissional professor, a fim de refletir sempre sobre suas aulas, atividades e condutas. Dessa maneira ele levanta três conceitos que integram o pensamento prático e a epistemologia da prática: o conhecimento na ação, reflexão na ação e reflexão sobre a ação e sobre a reflexão na ação.

\section{Resultados e discussões}

Esse trabalho está fundamentado a luz da teoria do profissional reflexivo de Schon (1983), esse autor visa a valorização da prática profissional, como um momento de construção do conhecimento pela reflexão, pela análise e pela problematização, assim o profissional torna-se o pesquisador de sua prática.

Essa proposta, inicia-se com o chamado: conhecer na ação, ele é realizado a partir de experiências adquiridas ao longo da vida profissional, a exemplo as práticas pedagógicas realizadas por um professor em sala de aula.

Quando o professor possui uma vasta experiência em sala de aula, muitas de suas ações e soluções de determinados problemas que surgem, são resolvidas de maneira tão simples e já se tornaram tão orgânicas a esse profissional, que ele é incapaz de descrevê-la. Mas se for necessário descrevê-las, consegue fazer ao observar e refletir sobre elas e com a descrição o conhecer na ação converte-se em conhecimento na ação, (Schon, 2000 e Gomez 1995).

Dando seguimento a esse pensamento prático e a epistemologia da prática reflexiva, segue-se a reflexão na ação, isto é, o pensar no que fazer no momento em que está atuando, interrompendo ou não a ação, assim é possível dar uma forma nova ao que se está fazendo, a reflexão na ação é um processo de grande riqueza ao profissional prático, pois pode ocorrer um confronto com alguma situação problema, que não estava prevista em seu conhecimento na ação, em vista disso, ele pode refletir e adotar novas formas de expor esse tema e solucionar os possíveis problemas.

Pode ocorrer que na sua reflexão na ação, mesmo não sucedendo nenhum problema, ele pode procurar uma outra forma de expor o que estava ministrando, visando também minimizar possíveis problemas, a partir da reflexão que ele teve no momento da

ParaOnde!?, Porto Alegre, v.12 n.2, p.73-80, 2019.http://seer.ufrgs.br/paraonde Edição Especial -III Colóquio de Pesquisadores em Geografia Física Ensino de Geografia 
aula. O professor reflete na ação, toda vez que é necessário reenquadrar uma situação problema que surge, procurando desenvolver respostas mais adequadas, (Goméz 1995; Zeichner 1995).

O último passo do processo que constitui o pensamento prático do professor é a reflexão sobre a ação e sobre a reflexão na ação, nesse ele pode realizar através da descrição de toda a sua ação. Nessa reflexão sobre a ação e sobre a reflexão na ação, a análise é realizada posteriormente a toda a execução da ação, essa reflexão pode vir a mudar a ação no futuro tomando outras decisões para a mesma, proporcionando novas forma de pensar e de compreender o processo de aprendizagem, (Goméz 1995; Schon 2000).

A reflexão sobre a ação analisa o conhecimento na ação e a reflexão na ação e os três formam o pensamento prático do profissional, com as quais ele pode enfrentar as mais variadas situações no dia-a-dia do âmbito escolar, (Gomez 1995).

Sob a luz da teoria do profissional reflexivo de Schon (1983), foi realizada essa proposta de modelo tátil de bacia hidrográfica para alunos cegos e com baixa visão. Baseado nas experiências com esses alunos, realizou-se a primeira parte da teoria de Schon (1983), o conhecimento na ação. Para isso, foram feitas várias narrativas de como essas aulas de hidrografia foram sendo realizadas anteriormente, a fim de buscar um produto que fosse capaz de representar uma bacia hidrográfica.

As discussões propostas nesse trabalho, se refere a técnica de confecção de um modelo tátil de bacia hidrográfica. Com as narrativas e os planejamentos que foram feitos na primeira etapa do trabalho, foi possível identificar um modelo que pudesse representar uma bacia hidrográfica. Buscou-se confeccionar a partir de um material que tivesse uma textura diferente e que pudesse demostrar as cotas altimétricas e o rio principal.

Os materiais escolhidos para confeccionar o modelo foram: isopor, papel machê de fabricação caseira, barbante e cola. Para o primeiro passo, foi impresso um mapa de cota altimétrica e recortado no isopor, figura 1.

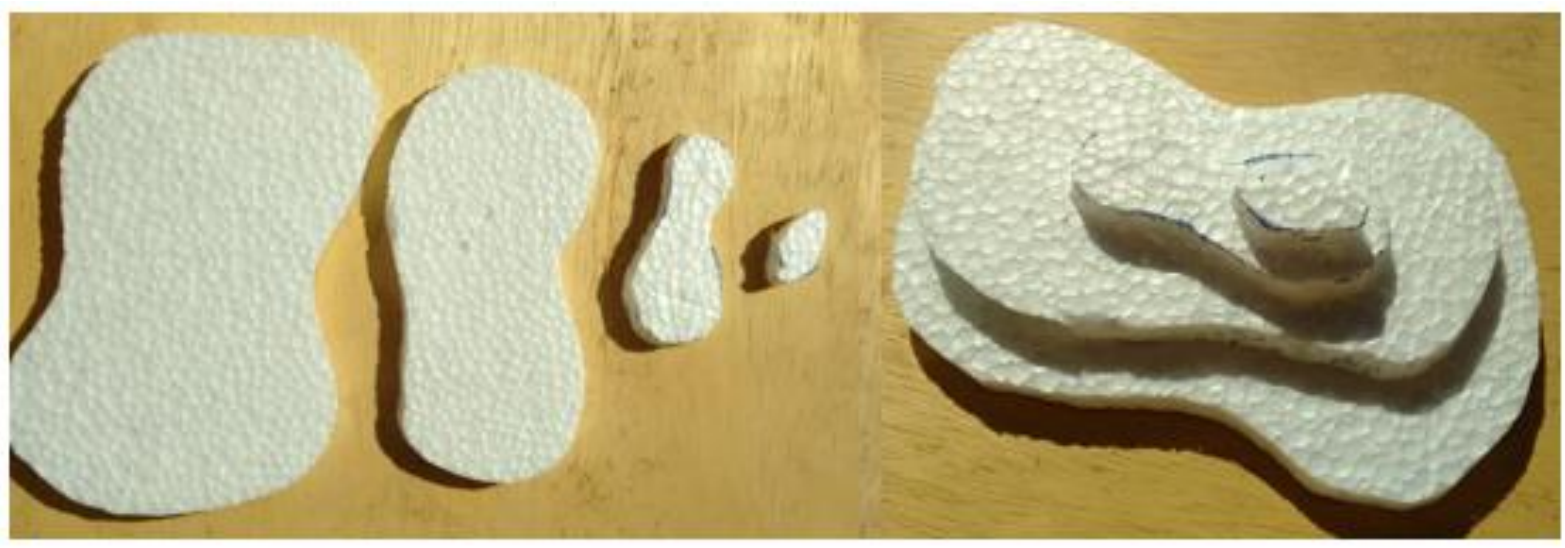

Figura 1 Cotas altimétricas no isopor Foto: Maryelle Mariano

Após essa etapa das cotas altimétricas, foi preparado uma massa de papel machê, a partir de papel higiênico picado e molhado, misturado a cola de trigo e água. Essa massa serviu para modelar, juntar e endurecer as cotas altimétricas do isopor e dar uma

ParaOnde!?, Porto Alegre, v.12 n.2, p.73-80, 2019.http://seer.ufrgs.br/paraonde Edição Especial -III Colóquio de Pesquisadores em Geografia Física Ensino de Geografia 
textura diferenciada para o modelo tátil. Após essa confecção do material, foi necessário deixar para secar para poder dar continuidade ao modelo tátil, figura 2.

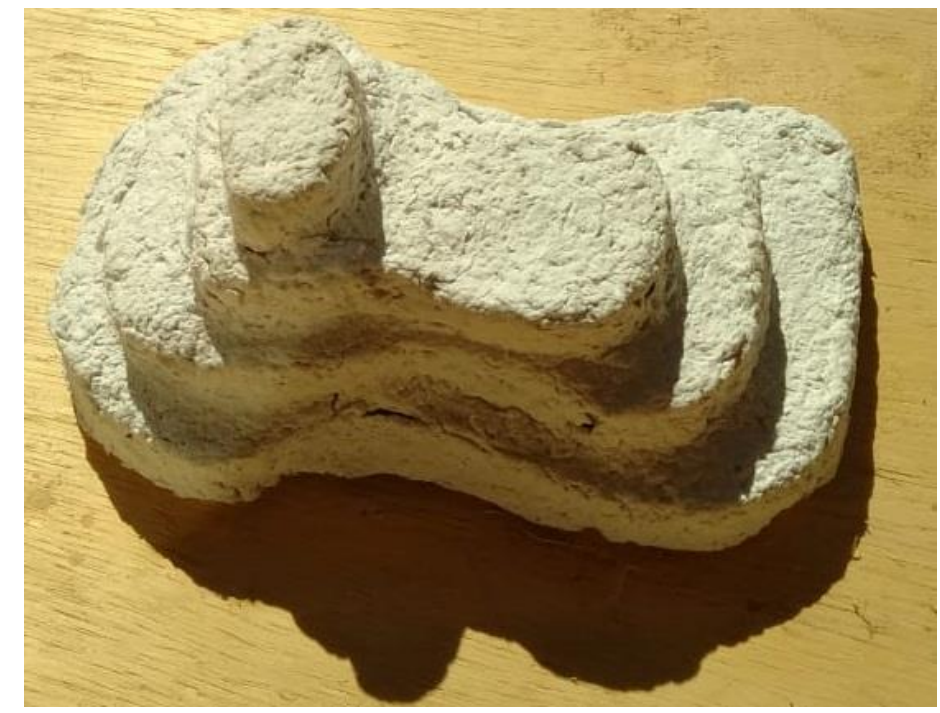

Figura 2 Modelo com papel machê. Foto: Maryelle Mariano

A última etapa da confecção do modelo tátil foi adicionar o barbante azul simulando um rio passando por esse relevo. Como os alunos de baixa visão podem apresentar diferentes níveis de perda visual, deu-se preferência por pintar o barbante de azul para se destacar do modelo branco. Devido a concentração do escoamento superficial se dar em áreas côncavas, a representação da drenagem foi colocada em apenas uma área, como demonstra a figura 3.

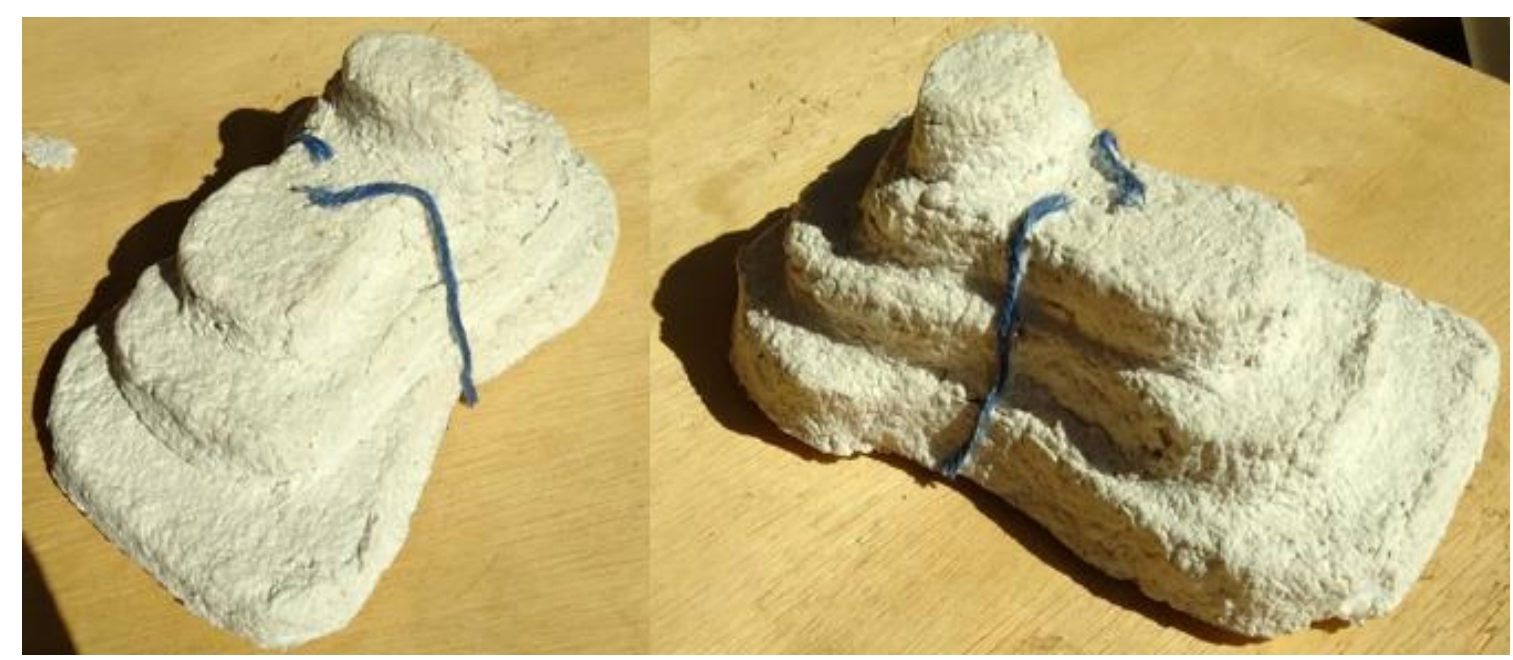

Figura 3 Modelo tátil finalizado. Foto: Maryelle Mariano

Com o modelo finalizado passamos as reflexões da última etapa proposta por Schon (1983), a reflexão sobre a reflexão na ação, dessa maneira, a reflexão se deu sobre a confecção do modelo e da efetividade do uso desse modelo em sala de aula. Durante o planejamento foi pensado e discutido de que maneira poderia ser utilizado com os alunos e como seria a sua confecção., 
Esse modelo permitirá ao aluno perceber a declividade do terreno, pois ao secar o papel machê enrijece, segura e define as cotas altimétricas dessa bacia hidrográfica representada. Além disso, é possível mostrar por onde um rio principal pode passar no terreno.

No planejamento da ação não foi levado em consideração uma área específica, como por exemplo, Bacia Hidrográfica do Paraná, apenas foi planejado que seria uma bacia hidrográfica que teria um rio principal, seus afluentes, a área e a vertente. $\mathrm{Na}$ confecção desse modelo, foi possível observar que a área escolhida não permitia fazer uma bacia hidrográfica com afluentes, pois faltavam áreas côncavas no modelo para inseri-los. Dessa maneira, para representar ao máximo possível o real, foi colocado apenas o rio principal.

A reflexão na reflexão da ação permitiu identificar esse obstáculo e a partir dele, os próximos modelos serão confeccionados de maneira que contemple uma área com afluentes e para o uso desse modelo, será necessário informar que a geomorfologia do terreno não possibilitou fazê-los.

Compreende-se que a reflexão na reflexão da ação foi um ponto importante para esse modelo confeccionado, pois levou a progredir no desenvolvimento da prática pedagógica e a construir novas soluções para o problema. Isso foi crucial para que em um próximo modelo, isso seja levado em consideração.

Espera-se com esse modelo que o professor consiga incluir em sua prática mais uma ferramenta de aprendizagem para seus alunos e que esse modelo possa servir de subsídios para criação de novas atividade táteis, proporcionando a seus alunos um momento de aprendizagem.

\section{Considerações finais}

Essa proposta de atividade foi desenvolvida e articulada com os preceitos da educação inclusiva, sugerindo assim, estratégias para o professor apresentar ao aluno com deficiência visual maneiras de perceber e aprender os conceitos estudados em sala de aula.

A teoria do profissional reflexivo de Schon (1983) permite ao professor refletir sobre a sua prática, dar novas respostas a questões e problemáticas que aparecem no seu cotidiano escolar.

A proposta desse trabalho é fornecer uma atividade pedagógica para alunos cegos e com baixa visão perceber o espaço ocupado por uma bacia hidrográfica, bem como os seus componentes principais. A teoria do profissional reflexivo de Schon (1983) permite o professor a refletir sobre a sua prática e promover outras formas de atividades pedagógicas que visem o aprendizado do aluno.

Ao fazer um planejamento de sua aula, ele se colocará em reflexão e assim poderá estar dialogando com as suas práticas e com os desafios que sempre aparecem em sala de aula. Não importa se a escola tem todos os recursos possíveis se o próprio professor não acredita em seu aluno e não está aberto a refletir sobre suas práticas, se entender que existirão momentos desafiadores na sua carreira e a partir disso buscar soluções para adaptar sua a aula aos alunos deficientes visuais, criará um ambiente inclusivo.

ParaOnde!?, Porto Alegre, v.12 n.2, p.73-80, 2019.http://seer.ufrgs.br/paraonde Edição Especial -III Colóquio de Pesquisadores em Geografia Física Ensino de Geografia 


\section{Referências}

ALMEIDA, R. D. de; PASSINI, E. O espaço Geográfico: ensino e representação. 15. ed.,2ª reimpressão - São Paulo: Contexto, 2008.

AMIRALIAN, M. L. T. M. "Sou cego ou enxergo? As questões da baixa visão." Educar. n. 23, p.15-28, 2004.

CASTELLAR, S. M. V. Educação geográfica: a psicogenética e o conhecimento escolar.: Caderno Cedes, Campinas, n.25, p.209-225, 2005.

GLAT, R; BLACO, L. de V. Educação Especial no contexto de uma educação inclusiva. In. GLAT, R (Org), Educação inclusiva: cultura e cotidiano escolar. Rio de Janeiro: 7Letras, p.15-35, 2009.

GOMES.A.P. O pensamento prático do professor: a formação do professor como profissional reflexivo. In: Os professores e a sua formação. Coautoria de António Nóvoa. 2. ed. Lisboa: Dom Quixote, 1995. SCHON.D.A.The reflective practitioner. New York. Basic Books, 1983.

SCHON. D. A. Educando o profissional reflexivo: um novo design para o ensino e a aprendizagem. Tradução Roberto Cataldo Costa. Porto Alegre: Artes Médicas Sul, 2000.

SCHON. D.A. Formar professores como profissionais reflexivos. In: Os professores e a sua formação. Coautoria de António Nóvoa. 2. ed. Lisboa: Dom Quixote, 1995.

SOUZA, J. G. de; KATUTA, A. M. Geografia e conhecimentos cartográficos: A cartografia no movimento de renovação da geografia brasileira e a importância do uso de mapas. São Paulo: Editora UNESP, 2001.

THOMA, A. S. A inclusão no ensino superior:"ninguém foi preparado para trabalhar com esses alunos (...) isso exige certamente uma política especial...". REUNIÃO ANUAL DA ANPED, v. 29, p. 1-18, 2006.

ZEICHNER.K. Novos caminhos para o practicum: uma perspectiva para os anos 90. In: Os professores e a sua formação. Coautoria de António Nóvoa. 2. ed. Lisboa: Dom Quixote, 1995. 